\title{
DOWN ARGENTINE WAY: LOS REMAKES DE PELÍCULAS ARGENTINAS EN HOLLYWOOD EN LOS AÑOS CUARENTA' ${ }^{1}$
}

Down Argentine Way: Remakes of Argentine Films in 1940's Hollywood

Alejandro Kelly HopfenblatT ${ }^{a}$

Instituto de Artes del Espectáculo Raúl H. CAstagnino

(Universidad de Buenos Aires) / CONICET

DOI: 10.15366/secuencias2020.51.005

\section{RESUMEN}

El creciente acceso a archivos internacionales y el fortalecimiento de redes globales han llevado en los últimos años a una reconsideración de numerosos preceptos sobre los cuales se ha basado la historiografía del cine. Uno de los campos fundamentales de esta renovación ha sido el de los cines nacionales, donde las perspectivas comparadas y trasnacionales han desplazado la mirada hacia las dinámicas globales y a los canales de circulación en que estas se insertaron.

El estudio de los remakes transnacionales configura un terreno de gran riqueza para esta renovación, ya que presenta la posibilidad de entrelazar prácticas industriales y comerciales, estrategias narrativas y transformaciones geopolíticas. En lo que respecta al período clásico, la preeminencia de Hollywood como nodo central de gran cantidad de transposiciones de textos internacionales hace que sea un foco ineludible al plantear investigaciones sobre estos films.

Entre la multiplicidad de países que se involucraron en la práctica del remake, un caso poco considerado es el de Argentina, que, a lo largo de los años cuarenta, tuvo dos películas propias que fueron adaptadas por el cine estadounidense: Los martes, orquídeas (Francisco Mugica, 1941) y Romance musical (Ernesto Arancibia, 1947), que se convirtieron en Bailando nace el amor (You Were Never Lovelier, William A. Seiter, 1942) y Romance en alta mar (Romance on the High Seas, Michael Curtiz, 1948), respectivamente. Ambas producciones de Hollywood presentaron comedias románticas insertas en films musicales ambientados en América Latina. El estudio comparado de los procesos que llevaron a la producción de los dos casos y las formas en que las cintas estadounidenses representaron escenarios y personajes latinos propone interrogantes que permiten complejizar y ahondar en aspectos novedosos de las políticas de Estados Unidos hacia Latinoamérica, las cambiantes relaciones del cine argentino con Hollywood y la tensión entre los imaginarios latinos y las imágenes cosmopolitas.

Palabras clave: Remakes, cine clásico argentino, cine clásico de Hollywood, cosmopolitismo, latinidad

\section{ABSTRACT}

The growing access to international archives and the strengthening of global networks have led in recent years to a reconsideration of various precepts of film's historiography. One of the main fields affected by this renewal is national cinemas' studies where transnational and comparative perspectives have brought forward global dynamics and circulation issues.

The study of transnational remakes constitutes a field of great wealth for this renewal since it presents the opportunity to intertwine industrial and commercial practices, narrative strategies and geopolitical transformations. Regarding classical cinema, given Hollywood's pre-eminence as center point of numerous international transpositions, it is an inescapable focal point that needs to be considered when researching these films. Among the multiplicity of countries that have been involved in transnational remakes, Argentina's case has been given little consideration. In the 1940's two Argentine movies were remade by Hollywood: Los martes, orquídeas (Francisco Mugica, 1941) and Romance musical (Ernesto Arancibia, 1947), which became Bailando nace el amor (You Were Never Lovelier, William A. Seiter, 1942) and Romance en alta mar (Romance on the

[1] Este artículo es parcialmente producto del trabajo desarrollado en el marco de una estancia de investigación en USC School of Cinematic Arts durante 2018 con una beca otorgada por la Comisión Fulbright y el Ministerio de Educación de la Nación. Los resultados presentados en este texto son posibles gracias al Warner Bros. Archive (School of Cinematic Arts, University of Southern California) y las colecciones de la Margaret Herrick Academy of Motion Pictures Arts and Sciences Library y Stanford University Libraries.
High Seas, Michael Curtiz, 1948) respectively. Both American films were romantic musical comedies set in Latin America.

A comparative study of the production processes of these movies and the way the Hollywood versions represented Latin environments and characters will open up questions that will help to have a more profound and complex notion of American policies on Latin America, Argentine cinema's volatile relationship with Hollywood, and the tension between Latin and cosmopolitan imaginaries.

Keywords: Remakes, classic Argentine cinema, classic American cinema, cosmopolitism, Latinity

[a] Alejandro Kelly Hopfenblatt es Doctor en Historia y Teoría de las Artes por la Facultad de Filosofía y Letras de la Universidad de Buenos Aires (UBA). Actualmente es becario posdoctoral del Consejo Nacional de Investigaciones Científicas y Técnicas (CONICET) con un proyecto sobre la cinematografía industrial latinoamericana en el período clásico radicado en el Instituto de Artes del Espectáculo (FFyL). Es miembro del Centro de Investigación y Nuevos Estudios sobre Cine (CIyNE, Facultad de Filosofía y Letras, UBA) y es socio de la Asociación Argentina de Estudios sobre Cine y Audiovisual (ASAECA) y la Latin American Studies Association (LASA) y ha realizado estancias de investigación en el Instituto de Investigaciones Históricas de la Universidad Nacional Autónoma de México (Fideicomiso Teixidor, 2014), la Facultad de Comunicación de la Universidad de Sevilla (AUIP, 2015) y School of Cinematic Arts, University of Southern California (FulbrightMinisterio de Educación, 2018). Ha publicado trabajos en numerosas revistas y libros colectivos nacionales y extranjeros. Es autor del libro Modernidad y teléfonos blancos. La comedia burguesa en el cine argentino de los años 40 (Ciccus, 2019), ganador del Tercer Concurso Nacional y Federal de Estudios sobre Cine Argentino Biblioteca ENERC - INCAA (2017). E-mail: alejandro.kelly.h@gmail.com 
La historia del cine ha sido contada tradicionalmente desde una mirada que ha privilegiado las fronteras geográficas como límites estructurantes de los relatos. Ello ha llevado a una focalización sobre los cines nacionales con causalidades y procesos explicados muchas veces por procesos políticos, económicos, tecnológicos y sociales internos. Frente a estas tendencias, el giro trasnacional que ha caracterizado los últimos años de los estudios del audiovisual ha permitido comenzar a dar mayor importancia a las circulaciones, intercambios y relaciones entre distintas cinematografías globales. Si bien el impacto de esta renovación ha sido mayor en los estudios dedicados a la producción contemporánea, también se han abierto nuevas perspectivas en la concepción cartográfica de la historiografía del cine.

Un campo sumamente propicio para estas transformaciones ha surgido en torno a los estudios dedicados a la circulación de textos dramáticos y la producción de diferentes versiones internacionales de los mismos relatos. Esta práctica, que existe desde los comienzos del cine, presenta ejemplos de sumo interés a lo largo de la historia del medio que cruzan marcos temporales y geográficos.

La investigación sobre los remakes ha permitido así poner en diálogo cinematografías diversas y establecer nuevas redes conceptuales. Como señalan Iain Robert Smith y Constantine Verevis, detenerse en adaptaciones transnacionales de los mismos argumentos obliga a reconsiderar las formas en que se producen, sus relaciones con los cines nacionales, su impacto sobre las representaciones de raza y género y las formas en que son recibidas por los espectadores $^{2}$. El análisis de estos ejes que atraviesan las dinámicas del remake permite iluminar aspectos muchas veces soslayados por la historiografía tradicional.

En este sentido, un caso de notorio interés por las características de su producción y los interrogantes que abre es el de dos comedias burguesas argentinas que fueron rehechas en Hollywood en la década de 1940: Los martes, orquídeas (Francisco Mugica, 1941) y Romance musical (Ernesto Arancibia, 1947). Sus guiones fueron adaptados en los Estados Unidos como musicales bajo los títulos de Bailando nace el amor (You Were Never Lovelier, William A. Seiter, 1942) y Romance en alta mar (Romance on the High Seas, Michael Curtiz, 1948), respectivamente. En ambos casos, los guionistas del texto original fueron Carlos Olivari y Sixto Pondal Ríos, quienes fueron figuras centrales de las transformaciones que vivió el cine de su país en esos años.

Ambas películas argentinas se entroncaban dentro del ciclo de comedias burguesas que tuvo su apogeo en este país a lo largo de la década. Con elementos de la comedia teatral francesa finisecular, la comedia de teléfonos blancos italiana y la screwball comedy de Hollywood, estas producciones incorporaron ambientes y temáticas cosmopolitas que festejaban la modernidad urbana y el mundo burgués ${ }^{3}$. No resulta casual, por lo tanto, que hayan llamado la atención de las filiales locales de los estudios estadounidenses que, entre otras funciones, se dedicaban a la adquisición de relatos internacionales.

Ahondar en estos remakes permitirá incorporar nuevos matices en el estudio de las relaciones establecidas durante el período clásico entre las ci-
[2] Iain Robert Smith y Constantine Verevis (eds.), Transnational Film Remakes (Edimburgo, Edinburgh, University Press, 2017).

[3] Alejandro Kelly Hopfenblatt, Modernidad y teléfonos blancos. La comedia burguesa en el cine argentino de los años '4o (Buenos Aires, Ciccus, 2019). 
[4] Iván Morales, «Luis Saslavsky: Hollywood vivido e imaginado" (AURA. Revista de Historia y Teoría del Arte, n. ${ }^{\circ}$, septiembre, 2016), p.33. Otros trabajos del autor que versan sobre las relaciones entre Hollywood y el cine argentino se pueden encontrar en "Las sombras llaman a mi puerta”: John Alton y el melodrama en Puerta cerrada (1939)» (Studies in Spanish \& Latin American Cinemas, vol. 16, n. $^{\circ} 3$, septiembre, 2019), pp. 295 - 314; «Escala en Buenos Aires: los primeros años de John Alton en el cine argentino" (Imagofagia, n. ${ }^{\circ}$ 17, abril, 2018), pp. 149-188.

[5] El boicot fue causado por la negativa de Argentina de declarar la guerra al Eje y las sospechas de infiltración nazi en el cine del país. Esta temática ha sido investigada en textos de diversos autores como Raúl Horacio Campodónico o Francisco Peredo, quienes, a partir de fuentes documentales y periodísticas, han reconstruido los debates hacia dentro de Argentina y Estados Unidos y las dinámicas diplomáticas y políticas que se pusieron en juego en ellos. Véase Raúl Horacio Campodónico Trincheras de celuloide. Bases para una historia político-económica del cine argentino (Madrid, Fundación Autor, 2005); o Francisco Peredo Castro, Cine y propaganda para Latinoamérica. México y Estados Unidos en la encrucijada de los años cuarenta (México DF, Centro de Investigaciones sobre América Latina y el Caribe, Universidad Nacional Autónoma de México, 2011).

[6] Ana M. López «Are All Latins from Manhattan?: Hollywood, Ethnography and Cultural Colonialism», en John King, Ana M. López y Manuel Alvarado (eds.), Mediating Two Worlds: Cinematic Encounters in the Americas (Londres, BFI, 1993), pp. 67-80. nematografías de Argentina y los Estados Unidos. En este sentido, resulta pertinente retomar las propuestas recientes de los trabajos de Iván Morales, que en los últimos años ha indagado en la multiplicidad y complejidad de intercambios entre ambos países durante la institucionalización de la industria fílmica rioplatense en la década de 1930. Como señala en su estudio sobre la figura del realizador Luis Saslavsky, el fantasma de Hollywood impactó sobre el medio argentino en la configuración de sus géneros narrativos, en los reclamos de modernización y sofisticación de la industria y en la formación del gusto del público. Sin embargo, esta relación no fue directa ni sencilla, sino que se articuló con los debates locales en torno a la identidad del cine, las tradiciones vernáculas y las tensiones surgidas a partir de la relación del país con el mundo ${ }^{4}$.

Las propuestas de Morales plantean una mirada teórica que puede ser expandida para adentrarse en la década de 1940. Con el contexto de la Segunda Guerra Mundial y su impacto sobre las dinámicas cinematográficas del continente, estos años presentan un conjunto de nuevas problemáticas que requieren ser consideradas para el estudio de estos remakes. Mientras que la bibliografía sobre la relación entre ambas naciones durante este período suele centrarse en el boicot operado desde aquel país para obstaculizar la entrada de película virgen en Argentina, los films considerados en el presente artículo abren el panorama a otras dinámicas de intercambio comercial y cultural 5 . Tanto los procesos de aburguesamiento y diversificación de la producción en el cine argentino como la búsqueda de mercados internacionales y las diversas tensiones políticas locales de la década fueron factores fundamentales en el desarrollo de estos vínculos.

Asimismo, estas películas se insertan dentro de un campo de producción cinematográfica en Hollywood en el que la temática latina comenzó a ocupar un lugar relevante. Ello se debió fundamentalmente al auge de las políticas de Buena Vecindad con las que Estados Unidos buscó garantizarse el apoyo de América Latina durante la Segunda Guerra Mundial. El medio cinematográfico supuso una de las principales herramientas a través de la cual se planteó la difusión de imaginarios de fraternidad panamericana que celebraban la hermandad entre naciones y promovían el American Way of Life.

En este contexto, el cine de los Estados Unidos se volcó en la producción de numerosas cintas ambientadas en diversos países de América Latina. Estas películas se produjeron en el marco de la Oficina de Coordinación de Asuntos Interamericanos (OCIAA) que se montó en 1941 para fomentar la producción de films panamericanistas y educar a los estadounidenses sobre el continente. Según señala Ana López, para 1945 se habían producido en total ochenta y cuatro películas de tema o ambientación latina. Entre ellos la autora destaca que existían tres variedades de relatos: aquellos en los que el protagonista estadounidense visitaba América Latina, los musicales clase B con artistas latinoamericanos y los musicales de mediana producción con artistas y temáticas de la región ${ }^{6}$. 


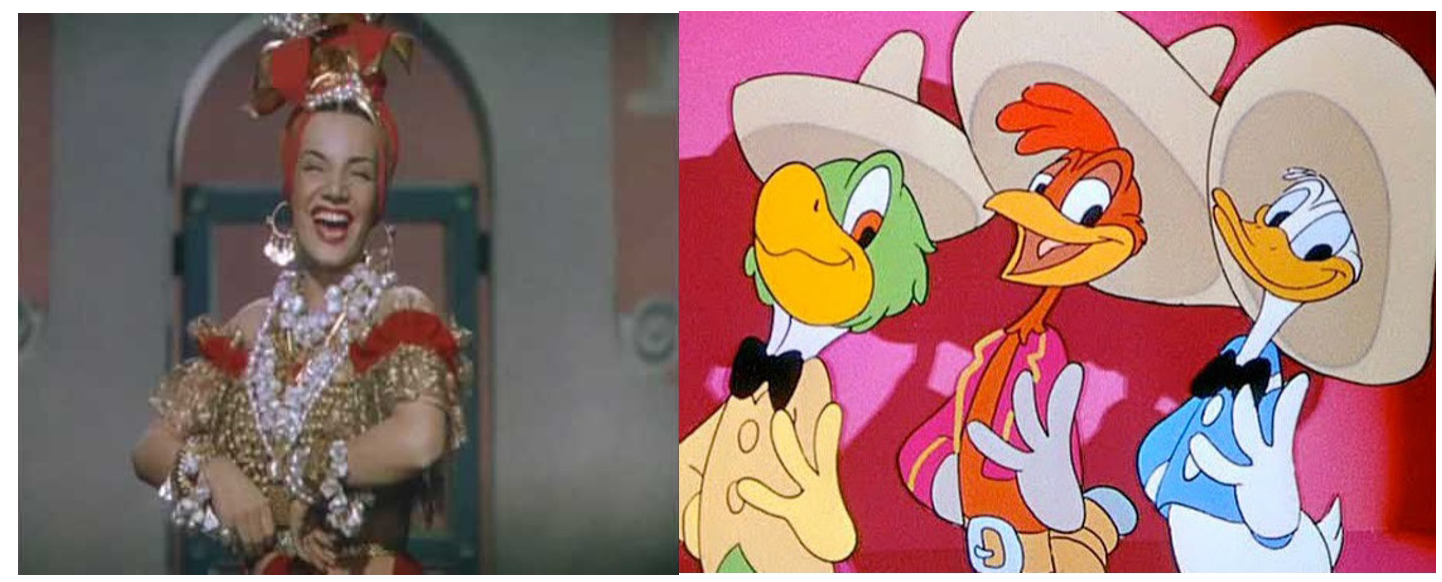

Algunos exponentes de las películas de Buena Vecindad: Carmen Miranda en Serenata tropical (Down Argentine Way, Irving Cummings, 1940) y el pato Donald en Los tres caballeros (The Three Caballeros, Norman Ferguson, Clyde Geronimi, Jack Kinney, Bill Roberts, Harold Young, 1944).

Las investigaciones que se han desarrollado sobre esta producción se han centrado usualmente en dos conjuntos de films: en primer lugar, aquellos que plantean una mirada caricaturesca de la región, muchas veces protagonizados por Carmen Miranda, como Serenata tropical (Down Argentine Way, Irving Cummings, 1940), Toda la banda está aquí (The Gang's All Here, Busby Berkeley, 1943); en segundo lugar, los cortometrajes de Walt Disney que fueron reunidos en Saludos amigos (Wilfred Jackson, Jack Kinney, Hamilton Luske, Bill Roberts, Norman Ferguson, 1942) y Los tres caballeros (The Three Caballeros, Norman Ferguson, Clyde Geronimi, Jack Kinney, Bill Roberts, Harold Young, 1944). El foco puesto sobre estas obras ha producido trabajos de gran interés que han versado sobre los debates internos en los Estados Unidos en torno a la representación de lo latino7 ${ }^{7}$, la historia de las representaciones de Brasil $^{8}$ y el impacto de estos films en los países de América Latina ${ }^{9}$.

Un aspecto poco señalado en estos estudios es el hecho de que para su producción se apelaba muchas veces a argumentos ya probados en textos fílmicos previos. Por ejemplo, como señala Debra Nan Walters, se daba el caso de relatos ambientados en París que eran trasladados a América Latina. Es así que Follies Bergere de Paris (Roy del Ruth, 1935), adaptación de una obra de Rudolf Lothar y Hans Adler, se convirtió en That Night in Rio (Irving Cummings, 1941) mientras que el director Mitchell Leisen filmó un remake de su película Midnight (1939) titulada Masquerade in Mexico $(1945)^{10}$. Si bien estos casos no suponían un mecanismo de adaptación transnacional, demuestran al mismo tiempo la avidez de Hollywood por acomodar textos diversos a las necesidades industriales del momento.

[7] Brian O'Neil «The Demands of Authenticity. Addison Durland and Hollywood's Latin Images during World War II», en Daniel Bernardi (ed.), Classic Hollywood, Classic Whiteness (Minneapolis, University of Minnesota Press, 2001), pp. 359-385; Penee Bender, Film as an Instrument of the Good Neighbor Policy, 1930s-1950s (Ann Arbor, UMI Microform, 2002).

[8] Bianca Freire-Medeiros, «Hollywood Musicals and the Invention of Rio de Janeiro, 1933-1953" (Cinema Journal, vol. $41, n .{ }^{\circ} 4$, verano, 2002), pp. 52-67; Lisa Shaw y Maite Conde, «Brazil through Hollywood's Gaze: From the Silent Screen to the Good Neighbor Policy Era», en Lisa Shaw and Stephanie Dennison (eds.), Latin American Cinema: Essays on Modernity, Gender and National Identity (Jefferson, NC, McFarland Press, 2005), pp. 180-209.

[9] Fernando Purcell, iDe película! Hollywood y su impacto en Chile, 1910-1950 (Santiago, Taurus, 2012).

[10] Debra Nan Walters, Hollywood, World War II, and Latin America: The Hollywood Good Neighbor Policy as Personified by Carmen Miranda (Tesis Doctoral, Los Angeles, University of Southern California, 1978). 
[11] Jennifer Forrest y Leonard Koos, Dead Ringers: The Remake in Theory and Practice (Albany, State University of New York Press, 2002).

[12] Leonardo Quaresima, «Loving Texts Two at a Time: The Film Remake» (CiNéMAS, vol. 12, n. ${ }^{\circ} 3,2002$ ), pp. 73-84. El carácter intrínsecamente industrial del remake en las primeras décadas del cine ha llevado a que su estudio sea planteado generalmente desde una visión negativa. Uno de los textos fundantes en este sentido es «Remade in USA», crítica de André Bazin (1952) de la versión estadounidense del clásico alemán $M$ (Fritz Lang, 1931) dirigida por Joseph Losey en 1951. Allí, el crítico francés plantea una visión crítica sobre las versiones que Hollywood hace de relatos extranjeros, renegando de su apropiación fetichista de imágenes originales sin reformular ni plantear propuestas originales. Del mismo modo, señala que las políticas de distribución del cine estadounidense terminan instalando su visión y su estilo, neutralizando los cines nacionales y ejerciendo un terrorismo económico sobre el comercio cinematográfico global. André Bazin, «Remade in USA» (Cahiers du Cinema, vol.2, n. ${ }^{\circ}$ 11, 1952), pp. 54-59.

[13] Este fue por ejemplo el caso de Intermezzo (Gregory Ratoff, 1939), remake del homónimo film sueco (Gustaf Molander, 1936), ambos protagonizados por Ingrid Bergman. El film de Hollywood retomaba así el vehículo que había hecho exitosa a la actriz en Estados Unidos para insertarla de modo más directo en este mercado.

[14] Se puede pensar, por ejemplo, en Cecil B. De Mille al rehacer su film de 1923 Los diez mandamientos (The Ten Commandments) en 1956 aprovechando la espectacularidad del color y el sistema VistaVision.
Los remakes de las películas argentinas en Hollywood se insertaron, por lo tanto, en ciclos de producción particulares de ambos países. Es el objetivo de este trabajo adentrarnos en estos dos casos para analizar las relaciones que se establecieron entre las cinematografías de Argentina y los Estados Unidos en los años cuarenta. En una década en la que la volatilidad de los vínculos entre las dos naciones impactaron en el mapa fílmico de la región, Bailando nace el amor y Romance en alta mar suponen objetos de estudio destacados para comprender las características de estas dinámicas. En función de este propósito, se considerará en primer lugar el rol jugado por empresas e individuos en el marco de las posibilidades abiertas por las políticas estatales de los dos países y su impacto sobre la producción. Asimismo se analizarán las formas de representación llevadas adelante por los films estadounidenses y los imaginarios que estos ofrecieron sobre Argentina y América Latina. Ahondar en ellos permitirá al mismo tiempo adentrarnos en las transformaciones que se produjeron dentro del cine de Hollywood en su forma de aproximarse al universo latino.

\section{Hollywood, Argentina y el remake cinematográfico}

En su célebre ensayo La obra de arte en la era de la reproductibilidad técnica, Walter Benjamin planteaba como característica fundamental del cinematógrafo su cualidad técnica, que borraba a sus producciones el aura propia de una obra de arte tradicional. Este carácter reproductivo se puede pensar no solamente en la duplicación de la película en cuanto objeto material, sino también en la posibilidad del medio fílmico de rehacer constantemente los mismos relatos.

Jennifer Forrest y Leonard R. Koos señalan que, ya desde los inicios del cine, se recurrió al remake como una forma de refinar mecanismos formales y técnicos o de ensayar propuestas narrativas. Más adelante en el tiempo, con el surgimiento del sistema industrial, esta práctica de repetición sirvió también como estrategia para volver a probar fórmulas exitosas y, con la consolidación del cine de autor, para plantear búsquedas estilísticas personales ${ }^{11}$.

Leonardo Quaresima sostiene que la conformación de un sistema de géneros cinematográficos dentro del modelo industrial implicó un proceso de regulación e institucionalización de la narrativa fílmica. Frente a ello, la práctica del remake se convirtió en una herramienta recurrente ligada a elementos nodales del sistema como la producción seriada, las estrategias publicitarias y los intercambios con las tradiciones de la cultura occidental ${ }^{12}$.

En el caso del cine clásico de los años treinta y cuarenta, estudiar los remakes permite trascender el análisis textual para identificar estrategias comerciales que excedían a la simple búsqueda de ganancias económicas. A pesar de la neutralización de relatos con identidades nacionales específicas, estas prácticas también podían ser utilizadas para introducir estrellas en el medio local ${ }^{13}$, actualizar temáticas en nuevos contextos técnicos ${ }^{14} \mathrm{o}$, como en el caso aquí estudiado, introducirse en políticas comerciales internacionales impulsadas por organismos estatales. 
La reapropiación de argumentos implicaba asimismo un mecanismo aceitado de comercialización de textos dramáticos a nivel internacional. Tino Balio señala que los principales estudios de Hollywood tenían oficinas en distintos países dedicadas a la búsqueda de relatos posibles de ser adaptados al cine. En este sentido, el autor sostiene que se procuraba retomar textos que ya habían sido probados frente al público masivo, pero que, al mismo tiempo, no implicaran mayores gastos económicos en su adquisición y transposición ${ }^{15}$.

Esta circulación constante de argumentos en el campo del espectáculo global refuerza la necesidad de considerar estos remakes desde las propuestas surgidas a partir del giro trasnacional. Como señala Nadia Lie, «el enfoque transnacional en el cine mundial implicaría un abandono de las concepciones binarias y a menudo opuestas entre diferentes cines (nacionales y otros), a favor de un modelo más dinámico y plural» ${ }^{16}$. La autora propone retomar la condición frágil e imaginaria del concepto de «nación» no para negarlo, sino para considerar su carácter mutuamente constitutivo con lo «trasnacional».

Lie destaca asimismo que el giro transnacional ha tenido un particular impacto sobre los estudios de cine hispánico a partir de tres factores fundamentales: la atención a las condiciones materiales del mercado cinematográfico, la pregunta por la construcción identitaria de los cines nacionales y las transformaciones estéticas y estilísticas de la producción fílmica. Si bien la autora destaca estas líneas en relación al período actual, resulta productivo trasladarlas al caso de los remakes en el cine clásico para proponer una mirada que conjugue las dinámicas industriales, la tensión entre lo local y lo regional y la producción de películas que dialogaron de forma directa con formas narrativas y de representación vinculadas a las cinematografías centrales.

Los remakes estudiados en este artículo pueden ser por lo tanto encarados desde esta perspectiva. Aunque el lugar central de Hollywood en estas dinámicas no puede ser negado, especialmente en lo que hace a las circulaciones de textos durante el período clásico, desde distintos puntos del planeta se han desarrollado investigaciones que dan cuenta de la multiplicidad y diversidad de casos. Trabajos, como los compilados por Smith y Verevis en Transnational Remakes, ponen de manifiesto, sin embargo, que el desarrollo de estas miradas en los estudios de los cines de Europa y Asia no ha tenido el mismo ritmo en América Latina. Los editores reconocen ya en su introducción esta disparidad y llaman la atención sobre la necesidad de integrarla dentro de los mapas de circulación global ${ }^{17}$.

La multiplicidad de factores implicados en el remake transnacional requiere asimismo prestar igual atención a los contextos de producción de ambos países involucrados. De este modo, más que indagar en los productos finales, esta mirada incorpora un estudio sobre los procesos y negociaciones que ilumina el lugar que estos films ocuparon en sus respectivas cinematografías y el impacto que tuvieron sobre las relaciones entre ambos países. En el caso aquí estudiado, es necesario pensar que, mientras que Hollywood se entusiasmaba con los musicales de temática latinoamericana, el cine argentino también vivía momentos de cambios.
[15] Citado en Constantine Verevis, Film Remakes (Edimburgo, Edinburgh University Press, 2006), p. 6.

[16] Nadia Lie, «Lo transnacional en el cine hispánico: deslindes de un concepto", en Robin Lefere y Nadia Lie (eds.), Nuevas perspectivas sobre la transnacionalidad del cine hispánico (Leiden/Boston, Brill Rodopi, 2016), p. 22.

[17] Véase Iain Robert Smith y Constantine Verevis, Transnational Film Remakes. 
Uno de los objetivos perseguidos por las comedias burguesas que ocuparon un lugar destacado en la producción cinematográfica local de la década de 1940 era la diversificación de la producción y la búsqueda de nuevos mercados internacionales. Mientras que los melodramas tangueros y las comedias de Luis Sandrini habían permitido ganar espacios en los circuitos de exhibición de América Latina en los primeros años de producción industrial, se esperaba que la incorporación de una vertiente cosmopolita abriera las puertas a las salas de Estados Unidos y Europa ${ }^{18}$.

Retomar los remakes de películas argentinas en Hollywood en los años cuarenta desde una perspectiva trasnacional centrada en las prácticas industriales y comerciales en que se produjeron permitirá, por lo tanto, iluminar aspectos donde la lógica de lo nacional y el análisis textual resultan insuficientes. No se busca negar la productividad de estos enfoques, sino articularlos con un abordaje que amplíe sus posibilidades de interpretación y abra nuevos interrogantes.

\section{Los martes, orquídeas: una ingenua suelta en Hollywood}

[18] Véase Alejandro Kelly Hopfenblatt, Modernidad y teléfonos blancos. La comedia burguesa en el cine argentino de los años '4o.

Resulta importante señalar que los remakes producidos en Estados Unidos se insertaron no solamente dentro de una práctica común de esta cinematografía, sino también dentro de un proceso de exportación de argumentos fílmicos desde Argentina. Como hemos señalado anteriormente, la década de 1940 fue también un momento de irrupción de reversiones de films argentinos en México, donde entre los años cuarenta y cincuenta se rehicieron más de 20 películas. En ellas, al igual que en los dos casos aquí estudiados, se privilegiaron las comedias sofisticadas que promovían visiones celebratorias de la modernidad urbana y el cosmopolitismo. Véase Alejandro Kelly Hopfenblatt, «Remakes y nuevas versiones en el marco de las industrias fílmicas de Argentina y México: tensiones entre las improntas nacionales y las ansias universales», en Ana Laura Lusnich, Alicia Aisemberg y Andrea Cuarterolo (eds.), Pantallas trasnacionales. El cine argentino y mexicano del período clásico (Buenos Aires, Imago Mundi, 2017), pp. 87-101
El proceso de aburguesamiento del cine argentino puede rastrear sus inicios hacia finales de los años treinta con films como Así es la vida (Francisco Mugica, 1939), donde comenzó a cambiar la forma en que se presentaba el universo de las clases medias y altas. Gradualmente la industria fílmica nacional, que hasta ese momento se había destacado por la primacía de una visión melodramática y temáticas vinculadas a los sectores populares, presenció la proliferación de comedias sofisticadas protagonizadas por jóvenes rubias y ambientadas en el mundo burgués. Este nuevo rumbo de la producción nacional pareció consolidarse en 1941 cuando, bajo el mando del mismo director, el 4 de julio se estrenó Los martes, orquídeas.

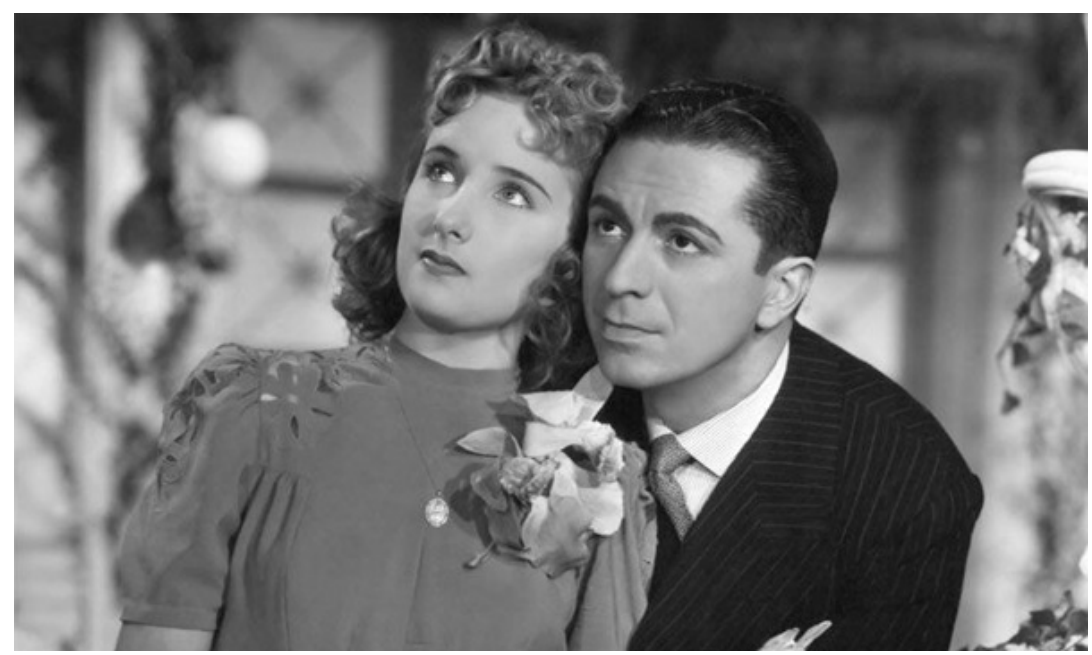

Mirtha Legrand y Juan Carlos Thorry en Los martes, orquídeas (Francisco Mugica, 1941). 
El film contaba la historia de Elenita Acuña, una adolescente virginal y soñadora (Mirtha Legrand), quien, inspirada por la lectura de novelas rosas, sueña con encontrar su hombre ideal. Su padre (Enrique Serrano), preocupado por el mundo de fantasías en que vive su hija, decide enviarle flores semanalmente para hacerle creer que tiene un pretendiente anónimo. Cuando la hija comienza a insistir con la necesidad de conocer la identidad de su enamorado, el hombre contrata a Cipriano, un joven pobre pero honrado (Juan Carlos Thorry), para que asuma ese rol. A partir de allí se suceden escenas de equívocos y falsas identidades hasta que se revela la verdad y triunfa el amor juvenil.

Los martes, orquídeas fue un éxito tanto en el campo de la crítica como con el público y con él se consolidó el ascenso de la comedia burguesa a un lugar central dentro de la producción fílmica local. Su impacto sobre el campo del entretenimiento se puede observar, por ejemplo, en los elogios del crítico y guionista Ulyses Petit de Murat, quien le dedicó una nota alabadora en el diario Crítica. Allí planteaba que por fin el talento de los realizadores argentinos había encontrado una forma de «incidir en el interés de la masa» y celebraba que para ello el film había logrado «divertir con limpieza, lejos de la asfixiante atmósfera cómica de los sainetes que luchaba por ahogar el nacimiento de un lenguaje realmente cinematográfico» ${ }^{19}$.

Al mismo tiempo Radiolandia, una de las principales publicaciones dedicadas al mundo del espectáculo, la proclamaba «la mejor comedia filmada en el país» y a sus guionistas, Sixto Pondal Ríos y Carlos Olivari, como «los libretistas más completos y con mejor sentido del cine del medio local» ${ }^{20}$. Cuatro meses después de su estreno, otra revista de circulación masiva, Sintonía, festejaba «Éxito extraordinario. Crítica y público están contestes en afirmar la calidad de la obra. [...] Inyecta savia nueva al cine argentino. Se esperaba el éxito, pero la reacción fue inesperada. Y - lo más interesante- marcó un rumbo. Fue y es nueva conquista» ${ }^{21}$.

En este marco, Lumiton, la compañía productora de la película, buscó diversificar su imagen ligada al entretenimiento popular y presentar una faceta más cosmopolita. Para ello emprendió diversas estrategias de modernización, entre las cuales se destacó un acuerdo con la firma estadounidense Columbia para que esta se encargara de la distribución de sus films en todo el continente america$\mathrm{no}^{22}$. Ello fue presentado por la prensa especializada de Estados Unidos como la punta de lanza de mayores acuerdos entre ambos países en términos cinematográficos, augurando futuros contratos entre otras empresas de ambos países ${ }^{23}$.

En esa misma sintonía, en septiembre de 1941, Variety informaba que el empresario Mel Shauer había decidido comenzar a insertar films argentinos en los circuitos de cine-arte estadounidenses para reemplazar la producción francesa que estaba menguando debido al conflicto bélico ${ }^{24}$. Allí se señalaba
[19] Ulyses Petit de Murat, «Significado del éxito de "Los martes, orquídeas"» (Crítica, n. ${ }^{\circ}$ 9282, 9 de junio de 1941), s/d.

[20] «Se ha estrenado, con "Los martes, orquídeas", la mejor comedia filmada en el país» (Radiolandia, n. ${ }^{\circ}$ 691, 14 de junio de 1941), s/d.

[21] «Sin título» (Sintonía, año VII, 29 de octubre de 1941, ${ }^{\circ}$ 407).

A tal punto llegó el impacto de Los martes, orquídeas que es posible encontrar notas periodísticas en diarios como $\mathrm{La} \mathrm{Na-}$ ción, Clarín o Buenos Aires Herald festejando los aniversarios de su estreno en 1981 y 1991.

[22] Los detalles del acuerdo y de su puesta en práctica son poco claros, ya que, si bien en la prensa cinematográfica se hacían menciones a su firma, no hubo luego mayor información. En un memorándum interno de la OCIAA de 1943 referido a la industria del cine argentino se señalaba que el acuerdo había sido finalizado debido a la insistencia de Lumiton para que Columbia invirtiera grandes sumas de capital en la producción de sus películas. «Folder Argentina-Report», Colección Motion Picture Society for the Americas, Special Collections, Margaret Herrick Academy of Motion Picture Arts and Sciences Library.

[23] Ray Josephs «Argentine Films Show Signs of Leading Spanish Field» (Variety, vol. $145, n .^{\circ} 5,7$ de enero de 1942), p. 91. Allí se señala que, al igual que Lumiton, la compañía argentina Sur Art Film había firmado un contrato para la distribución de su producción con United Artists. Este acuerdo, sin embargo, fue de corta duración, ya que Sur Art llegó a filmar solamente una película antes de cerrar sus puertas.

[24] Los vínculos de Shauer con la Argentina fueron seguramente fomentados por el hecho de que su esposa fuera la actriz española radicada en Hollywood Rosita Moreno, quien había actuado en dos películas de Carlos Gardel y en diversas cintas argentinas como El canillita y la dama (Luis César Amadori, 1939) y La hora de las sorpresas (Daniel Tinayre, 1941). 
[25] «Argentine Pix Seek Distrib Extension in U.S.; Shauer, Moreno Behind Move» (Variety, vol. 144, n. ${ }^{\circ} 3$, September 24, 1941), p. 16 .

[26] «Los martes, orquídeas» (Variety, vol. 143, n. ${ }^{\circ} 3$, June 25, 1941), p. 20.

[27] Francisco Peredo Castro, Cine y propaganda para Latinoamérica. México y Estados Unidos en la encrucijada de los años cuarenta. (México D.F., Centro de Investigaciones sobre América Latina y el Caribe, Universidad Nacional Autónoma de México, 2011).

[28] «Producción argentina» (El Heraldo del Cinematografista, vol. XII, n. ${ }^{\circ} 551,11$ de marzo de 1942), p. 33 .

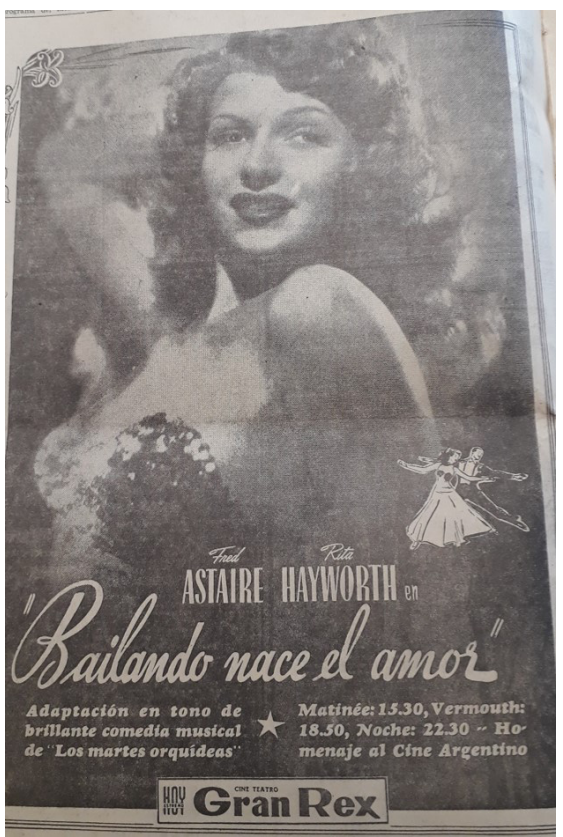

Publicidad de Bailando nace el amor (Diario La Nación, 13 de mayo de 1943) piense $»^{26}$. que, hasta el momento, los principales mercados para estas películas eran las zonas hispanohablantes de California, Texas y Nueva York, pero que, según consideraciones del empresario, alrededor de un cuarto de la producción argentina podía integrarse en estos circuitos alternativos. Los dos primeros títulos elegidos por Shauer para probarlo fueron Historia de una noche (Luis Saslavsky, 1941), adaptación de una obra del austríaco Leo Perutz, y Los martes, orquídeas ${ }^{25}$.

La idea de comercializar el film de Mugica en el mercado estadounidense ya se había hecho presente en la crítica del film que había escrito el corresponsal de Variety en Argentina. Allí se señalaba que, si los comités de intercambio estaban buscando películas de este país para llevar a los Estados Unidos, esta era ideal pues no solo apelaba a los públicos extranjeros, sino también a los propios estadounidenses. Esta propuesta se basaba fundamentalmente en la figura de Mirtha Legrand, quien, siendo rubia, atractiva y simple, era «definitivamente no lo que un norteamericano promedio piensa que es una sudamericana, sino, según todo lo indica, lo que aquí quieren que se

Al mismo tiempo, el accionar de Columbia en el país estaba ligado a los intereses de los Estados Unidos en la región. Francisco Peredo Castro señala que la empresa actuaba al mismo tiempo como un informante para su gobierno sobre el accionar de enviados alemanes en el mundo del cine argentino. De este modo, sus prácticas comerciales deben ser pensadas dentro de una lógica mayor de acción en conjunto con las líneas directrices del consulado estadounidense en la Argentina ${ }^{27}$.

Fue en este contexto que en marzo de 1942 se anunció que Columbia había comprado el argumento escrito por Pondal Ríos y Olivari para hacer su propia versión de la obra ${ }^{28}$. A partir de allí, el campo cinematográfico local comenzó a seguir con atención su rodaje mientras se festejaba que la principal industria cinematográfica global hubiera elegido un film nacional para adaptar.

Sin embargo, mientras fue avanzando la producción del film, la algarabía comenzó a enfriarse. El principal problema radicaba en la neutralización y estandarización de temáticas y personajes. La cándida adolescente Elenita interpretada por Mirtha Legrand había pasado a ser en María, encarnada por Rita Hayworth, un personaje que desechaba la ingenuidad de la argentina y retomaba el imaginario hegemónico de la mujer latina ligado a la fogosidad y el temperamento. Cipriano, por su parte, que había sido interpretado por Juan Carlos Thorry como un hombre trabajador y humilde, se había convertido en la piel de Fred Astaire en Bob, un bailarín estadounidense arrogante y seductor. De este modo, la sencillez que había caracterizado a los personajes argentinos 
había sido desplazada por una composición ligada a imaginarios universales con menos matices.

Frente al estreno de Bailando nace el amor en Los Ángeles, June Marlowe, corresponsal de Radiolandia en Hollywood, lamentó la transformación de la «comedia candorosa y romántica» en una «aparatosa comedia musical». El único aspecto positivo que encontró la cronista fue la presentación de Buenos Aires «como una ciudad cosmopolita, olvidándose de la legendaria figura del gaucho tan arbitrariamente usada en ocasiones anteriores ${ }^{29}$. Luego de estos reportes el film comenzó a ocupar un lugar menor en la prensa local, lo cual fue acompañado por una débil campaña publicitaria por parte de Columbia en Argentina.

El menguante interés por el film llevó incluso a que su estreno se pospusiera una semana dado el éxito que estaba teniendo otro film realizado en el marco de las políticas de Buena Vecindad, Mi secretaria brasileña (Springtime in the Rockies, Irving Cummings, 1942), protagonizado por Carmen Miranda ${ }^{30}$. Cuando finalmente, el 14 de mayo de 1943 se estrenó en el cine Gran Rex, la película recibió una recepción tibia y ambivalente en la que se celebraba, por un lado, que el film argentino hubiera sido superior, pero se lamentaba asimismo la oportunidad perdida. Luego de solamente dos semanas, Bailando nace el amor salió de los circuitos del centro de Buenos Aires para comenzar su recorrido por las salas de los barrios porteños y las provincias argentinas sin dejar mayores marcas en su paso por las pantallas nacionales.

La ambivalencia que acompañó el estreno de la película se dio en el contexto de una industria que había comenzado a sentir el impacto de los cambios en la política hacia la región desde Estados Unidos. Francisco Peredo Castro señala que en junio de 1942 se firmó entre Estados Unidos y México un acuerdo de colaboración con el que se fomentaría el crecimiento de la industria mexicana a partir de la renovación técnica, el apoyo financiero y el fortalecimiento de la distribución regional ${ }^{31}$. En esos mismos meses comenzó la política de boicot y supresión de comercialización de película virgen hacia Argentina que significaría una caída de la producción fílmica, una pérdida de mercados internacionales y un creciente malestar en las relaciones entre el cine argentino y el estadounidense. En este contexto, las distintas dinámicas establecidas a partir del interés de Hollywood por la potencia de la cinematografía argentina fueron enfriándose, y el caso del remake de Los martes, orquídeas pareció transformarse en un momento singular de las relaciones de ambos países.

\section{Romance musical: una cancionista en alta mar}

Las políticas de Buena Vecindad que signaron la relación de Hollywood y América Latina en la primera mitad de la década de 1940 comenzaron a decaer una vez terminada la Segunda Guerra Mundial. En el marco de la reorganización de fuerzas en la posguerra, la región pasó a ser un espacio marginal dentro de las nuevas dinámicas globales. En este contexto, hubo un marcado descenso cuantitativo de relatos con ambientación al sur del Río Grande.
[29] June Marlowe, «El candor romántico de 'Los martes, orquídeas' perdiose en su nueva concepción espectacular» ( $R a-$ diolandia, $n .^{\circ} 779,20$ de febrero de 1943), s/d.

[3o] «'Bailando nace el amor' se posterga; continuará "Mi secretaria brasileña"» ( $\mathrm{La} \mathrm{Na-}$ ción, 5 de mayo de 1943), p. 8.

[31] Véase Francisco Peredo Castro, Cine y propaganda para Latinoamérica. 
[32] Penne Bender, Film as an Instrument of the Good Neighbor Policy, 1930s-1950s.

[33] Clara Kriger, Cine y peronismo. El Estado en escena (Buenos Aires, Siglo XXI, 2009).
Penne Bender señala en este sentido que los musicales de temática latinoamericana fueron perdiendo terreno, aunque subsistieron por una década con títulos como Camino de Río (Road to Rio, Norman Z. McLeod, 1947), Me besó un bandido (The Kissing Bandit, Laslo Benedek, 1948) y Latin Lovers (Mervyn LeRoy, 1953). Asimismo, en las representaciones de la región, el espíritu fraterno y festivo comenzó a ser suplantado por otras propuestas que la presentaban como reductos de gánsteres, ambientes de cabaret o refugios de criminales nazis en películas como Acorralado (Cornered, Edward Dmytryk, 1945), Gilda (Charles Vidor, 1946) y Tuyo es mi corazón (Notorious, Alfred Hitchcock, 1946) ${ }^{32}$.

Al mismo tiempo, el apoyo de Washington y Hollywood hacia México fue también decayendo, mientras que con Argentina se mantuvo una relación tirante y hostil. Clara Kriger señala que desde Estados Unidos se mantuvieron diversas políticas de retacear el envío de material virgen a la Argentina, lo cual fue contestado con el bloqueo de los fondos que devengaban las películas estadounidenses y acciones legales contra las principales distribuidoras de Hollywood. Mientras tanto, el cine argentino fue gradualmente saliendo de la crisis generada por la escasez de celuloide gracias a la intervención activa del Estado y el cambiante escenario internacional de posguerra ${ }^{33}$.

En lo que respecta a su producción, el proceso de aburguesamiento comenzado hacia finales de la década anterior siguió vigente, y se profundizó la diversificación de la producción local. Si bien no se dejaron de realizar cintas de corte popular, comenzaron a proliferar adaptaciones de grandes obras de la literatura universal, policiales urbanos, melodramas eróticos y comedias sofisticadas. En ellos se proponían imaginarios de modernidad y cosmopolitismo y formas de representación ligadas a imaginarios universales.

Este escenario llevó a que, incluso las figuras más vinculadas a las narrativas populares, tuvieran que insertarse y negociar con estas nuevas modalidades. Entre ellas se contó Libertad Lamarque, estrella de melodramas tangueros, quien debió diversificar sus personajes entre estos caminos. Al mismo tiempo que encarnaba una actriz del teatro popular en La cabalgata del circo (Mario Soffici, 1945), protagonizaba comedias sofisticadas como Eclipse de sol (Luis Saslavsky, 1943) o su último film antes de partir al exilio en México, Romance musical.

El film tenía como protagonista a Mecha (Lamarque), una cancionista contratada por una mujer de clase alta para tomar su lugar en un crucero que parte de Buenos Aires hacia La Habana mientras ella se queda en Argentina espiando a su esposo. Este, al sospechar de una posible infidelidad, contrata a un detective privado (Juan José Míguez) para que siga a su mujer en el barco. El agente conoce a Mecha en el viaje y comienzan un romance, ambos bajo falsas identidades. El film continúa así sumando enredos hasta que, al llegar a Cuba, se revela la verdad y triunfa el amor.

Tanto la actriz como el carácter internacional de su interpretación fueron los ejes principales sobre los cuales se planteó la publicidad del film. Un anun- 


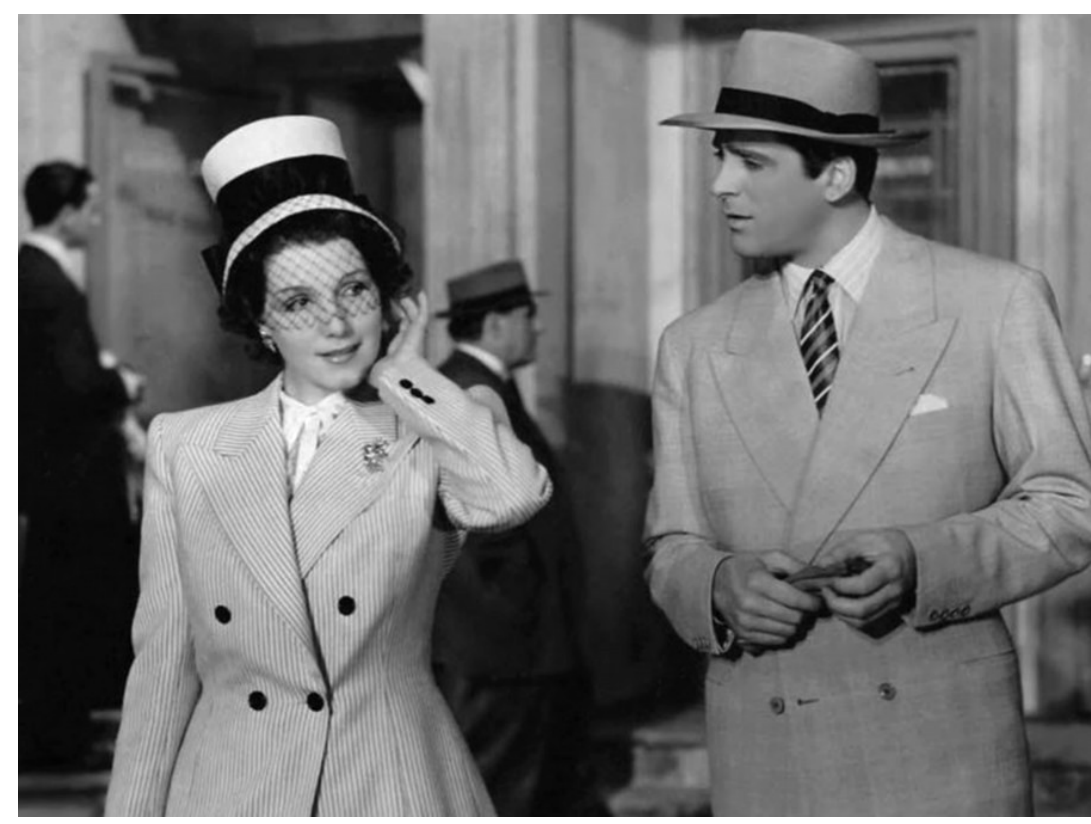

Libertad Lamarque y Juan José Míguez en Romance musical (Ernesto Arancibia, 1947).

cio aparecido en el diario La Nación el 22 de enero prometía «Música de todos los ritmos. El tango melodioso. La rumba que seduce. El vals que emociona. El swing que electriza. La conga que arrastra» ${ }^{34}$. De este modo se señalaba la diversificación que esta película implicaba en el repertorio de la estrella, mientras que al mismo tiempo se explicitaba la inserción de este film dentro de una lógica más internacionalista y cosmopolita.

Sin embargo, a diferencia de Los martes, orquídeas, el impacto de Romance musical no fue mayor, pues suponía más bien una continuidad de ciertas ideas ya presentes en el cine nacional. El crítico de La Nación, por ejemplo, señalaba que «...todo se desenvuelve alrededor del motivo clásico de los celos. No se ha querido, sin embargo, desviar el film de su camino sonriente y por eso se mantiene en el terreno de una comicidad fácil y comunicativa»35. Mientras que a comienzos de la década la crítica encontraba en este tipo de películas algo novedoso y prometedor, a esta altura ya se había convertido en un repertorio usual y genérico de la cinematografía local.

A diferencia de Los martes, orquídeas, donde su éxito nacional y su cosmopolitismo había sido el motor para que fuera rehecha en Hollywood, en este caso los mecanismos que llevaron a su remake pasaron por otro lado. En su comentario para el diario El Mundo, el crítico Calki observaba que «como detalle de interés, la película argentina, del sello San Miguel, estrenada ayer en el Normandie, ofrecía el hecho de que su argumento de Pondal Ríos y Olivari fue adquirido para ser filmado en Hollywood» ${ }^{36}$.
[34] Publicidad de Romance musical (La Nación, 22 de enero de 1947), p. 8.

[35] «Buen humor y canto en 'Romance musical'» ( $\mathrm{La} \mathrm{Na-}$ ción, 23 de enero de 1947), p. 8.

[36] «Nueve canciones y un enredo risueño en 'Romance musical'» (El Mundo, 23 de enero de 1947), p. 14. 
[37] «Facsímil del contrato de Olivari y Pondal Ríos con Estudios San Miguel, 30 de julio de 1945». Carpeta «Romance on the High Seas, Story File, 2 of 4", Warner Bros. Archive.

[38] Nota escrita a mano. Carpeta «Romance on the High Seas, Story File, 3 of 4», Warner Bros. Archive.

En el original:

Darling: if the deal is consummated would you please send us a wire saying: «Through this agency, Warner Brothers bought an original screenplay from Southamerican top-writers Pondal Rios and Olivari».

We need it for publicity purposes.
Destacados por la crítica argentina como dos de los nombres principales del cine y el teatro local, los guionistas se habían posicionado desde comienzos de la década en un lugar destacado del campo del entretenimiento. Luego del éxito internacional de películas que escribieron, como Kilómetro 111 (Mario Soffici, 1938) o Adolescencia (Francisco Mugica, 1942), la dupla había incursionado en una carrera internacional. En ese marco ya habían comenzado a comercializar sus propios textos como en el caso del film mexicano Su última aventura (Gilberto Martínez Solares, 1946), que retomaba el argumento de la cinta argentina Persona honrada se necesita (Francisco Mugica, 1941).

A diferencia de Los martes, orquídeas, cuya adquisición por Columbia había sido fruto de su éxito comercial, en esta ocasión la venta del guion precedió incluso al estreno del film argentino y se debió principalmente al accionar de sus autores. Ya en el contrato que habían firmado con los estudios San Miguel en julio de 1945 para la producción de la cinta original se estipulaba que

1) Quedan Uds. en libertad de autorizar versiones del mismo argumento en otra lengua que no sea la española

2) La versión que de acuerdo a la autorización conferida en el artículo anterior se realice podrá ser exhibida en todos los países del mundo, inclusive en la Argentina

3) La película en otro idioma no podrá ser exhibida «doblada al castellano» en la Argentina

4) Siendo el título de nuestra versión patrimonio exclusivo de estos Estudios, no podrá ser utilizado por Uds. para la autorización de otra película, ni en la Argentina, ni en ninguna otra parte del mundo ${ }^{37}$.

Con estas condiciones quedan claras las intenciones desde un inicio por parte de los guionistas de vender su texto por fuera de América Latina. Aunque los documentos existentes no permiten vislumbrar quién llevó adelante el primer acercamiento entre ellos y Warner Bros., a mediados de 1946 ya estaban en tratativas para desarrollar este remake. La importancia comercial de esta transacción para ellos se evidenciaba en una nota que dirigieron a «Beatrice», la intermediaria encargada de la venta de su guion a través de la agencia Lou Irwin Agency. Allí le solicitaban que

si el acuerdo se concreta, envíanos por favor un cable que diga «A través de esta agencia, Warner Brothers compró un guion original a los destacados escritores sudamericanos Pondal Ríos y Olivari».

Lo necesitamos para fines publicitarios ${ }^{38}$.

El acuerdo final se firmó en noviembre de 1946, antes del estreno de la producción argentina, e inmediatamente Warner Bros. comenzó a trabajar en la nueva versión bajo los títulos de Musical Romance o Romance in High C. Esta adaptación permitía mayor libertad en su ambientación que los escenarios de la burguesía nacional de Los martes, orquídeas. Aquí, el crucero latinoamericano invitaba a adoptar una mirada más ligada a una impronta turística sobre la región y se cambiaron los países donde transcurría el relato. La pelí- 


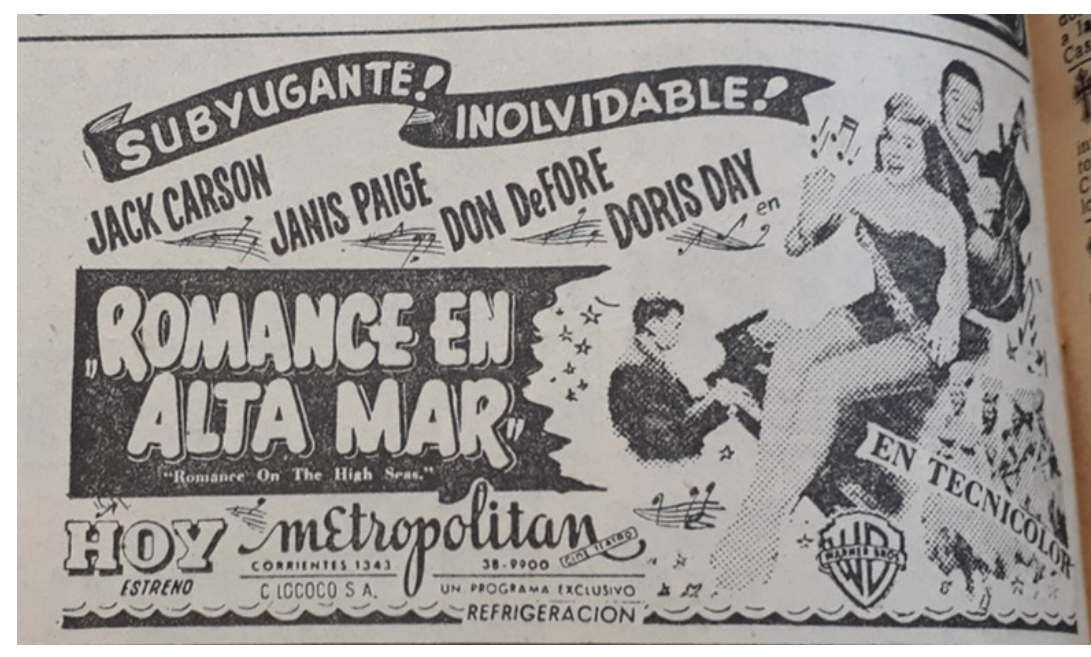

Publicidad de Romance en alta mar (Diario La Prensa, 8 de diciembre de 1948).

cula de Curtiz prescindió por completo de cualquier ciudad argentina y planteó un relato donde el viaje comenzaba en Estados Unidos, se detenía en Cuba y Trinidad y llegaba finalmente a Río de Janeiro.

Esta modificación, que podría haber sido vista de modo negativo en una cobertura periodística similar a la que recibió Bailando nace el amor en la Argentina, pasó aquí mayormente desapercibida en el marco de una fría recepción en el medio cinematográfico nacional. Estrenada el 8 de diciembre de 1948 en el cine Metropolitan del centro porteño, Romance en alta mar pasó rápidamente a los circuitos de exhibición secundarios. Las críticas, por su parte, tomaron a la película como una producción más de Hollywood, sin ningún atractivo y, si bien se hacía referencia al hecho de que el argumento original era de Pondal Ríos y Olivari, en ningún caso se especificaba el título del original ${ }^{39}$.

Estas transformaciones tanto en el terreno de la comercialización del cine nacional como en la recepción crítica de este remake marcan un claro contraste en la forma que tanto Argentina como Estados Unidos encararon sus relaciones hacia finales de la década. Mientras que había menguado el interés de las políticas estatales ligadas a la Buena Vecindad, al mismo tiempo el discurso que primaba en la crítica argentina buscaba desentenderse de la sombra de Hollywood sobre la cinematografía local. Ello se puede observar tanto en la fría repercusión periodística de esta producción como en el hecho de que su existencia se haya debido exclusivamente a esfuerzos individuales de agentes privados. Como veremos a continuación, estas transformaciones no fueron solamente en el terreno de la producción, sino que también incidieron en los cambios narrativos que supusieron las adaptaciones y el modo en que Hollywood buscó representar los escenarios latinos.
[39] Una posible explicación para ello sea también el protagonismo de Lamarque en el film nacional, quien para este momento ya se encontraba exiliada del país luego de entrar en conflicto con el gobierno peronista. 


\section{Representando una Latinoamérica moderna}

Para comprender las formas de representación adoptadas por los remakes de films argentinos en Hollywood en los años cuarenta es necesario primero detenerse en un aspecto más general que enmarca a las películas de temática y ambientación latina producidas en Estados Unidos en esos años. Como señala Ana López, gran parte de ellas se insertaron en el terreno de los films musicales, asociadas a una idea exótica de latinidad relacionada con formas rítmicas como la rumba, el mambo y la samba ${ }^{40}$. Al mismo tiempo, Arthur Freed, director de la unidad productora de musicales en MGM, señalaba a mediados de la década que:

Creo que la solidaridad hemisférica, la buena vecindad y ese tipo de cuestiones son solo una razón secundaria para la inundación de películas sudamericanas. La verdadera razón es la música de Sudamérica. El swing, que ha ocupado el lugar central en los últimos cinco o seis años, está decreciendo y la rumba está saltando a la primera posición en el gusto americano ${ }^{41}$.

[40] Ana M. López, «Are All Latins from Manhattan?: Hollywood, Ethnography and Cultural Colonialism».

[41] Charles Affron y Mirella Jona Affron, Best Years: Going to the Movies, 1945-1946 (New Brunswick and London, Rutgers University Press, 2009), p. 69. En este sentido se debe señalar la estrecha relación de la industria fílmica con la discográfica, lo cual requiere mayor investigación. Como ejemplo de esta convergencia de intereses, a los pocos meses del estreno de Bailando nace un amor en Argentina, Variety destacaba que dos de sus temas musicales (Dearly Beloved y Chiu Chiu) se encontraban entre los singles más vendidos en las disquerías porteñas. «Argentina's Best Sellers» (Variety, vol. 152, n. ${ }^{\circ} 4$, October 6, 1943), p. 46.

[42] La versión final del guion, fechada el 4 de junio de 1942, no presenta referencia a las imágenes iniciales de Buenos Aires, pero sí plantea en algunos momentos utilizar vistas de la ciudad como fondo para algunas de las acciones del film. «You Were Never Lovelier-Revised Final Draft», Collection Number Mo192. Guide to Delmer Daves Papers 1930-1965, caja 11, carpeta 13 .
La música y el ambiente festivo eran elementos fundamentales en la constitución de estas películas, y a través de ellos se apelaba a una idea de latinidad similar a la encarnada por Carmen Miranda, que presentaba una alteridad con respecto al público estadounidense. Sin embargo, en el caso de los remakes de films argentinos se presentaba una particularidad prácticamente ausente en aquellos. Sin negarse la festividad inherente a la música local, esta era incorporada en relatos que destacaban en sus imágenes y discursos la modernidad y el cosmopolitismo de sus escenarios.

Tanto Bailando nace el amor como Romance en alta mar presentaban grandes urbes donde los personajes estadounidenses se veían envueltos en alocados enredos similares a los de cualquier film de Hollywood. Sin embargo, el modo en que ambas películas mostraban este mundo era claramente distinto, relacionado con los diferentes modos en que se encaró en cada caso el remake del argumento argentino.

Bailando nace el amor establecía desde un primer momento su locación con un cartel que indicaba que la acción se situaba en Buenos Aires e imágenes que mostraban el centro porteño, la Plaza de Mayo y el Congreso Nacional. Luego se introducía otro cartel - «Palermo Race Track»- que ubicaba la acción en el hipódromo. Sin embargo, luego de presentar al personaje de Bob (Fred Astaire) asistiendo a las carreras en el hipódromo de Palermo, esos registros documentales desaparecían. De allí en más la acción pasaba a transcurrir casi exclusivamente en el hotel de la familia Acuña, un establecimiento de espíritu cosmopolita que permitía insertar personajes internacionales sin demasiadas justificaciones del guion.

Antes de tomar el título de You Were Never Lovelier, el argumento había sido elaborado bajo el nombre Carnival in Rio, lo cual ya señalaba que la ciudad específica donde transcurría la acción era indistinta en la adaptación ${ }^{42}$. 

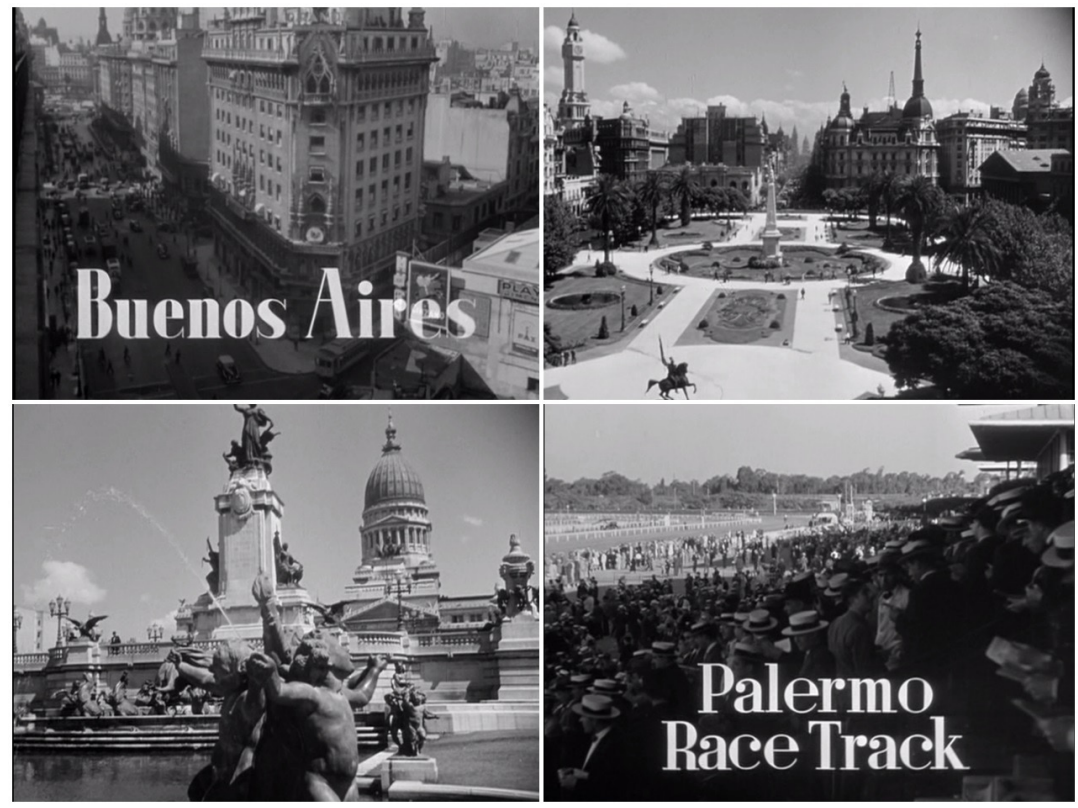

Registros documentales de Buenos Aires en el inicio de Bailando nace el amor (You Were Never Lovelier, William A. Seiter, 1942).

Buenos Aires pasó así a ser una ciudad tropical asociada al imaginario latino que dominaba los musicales latinoamericanistas de Hollywood de esos años. A lo largo del film, las referencias a Argentina o Buenos Aires eran nulas y se priorizaba siempre hablar con nombres más globalizadores. Por ejemplo, cuando María conversaba con su familia sobre la posibilidad de que Bob vuelva a los Estados Unidos, exclamaba «él no dejará Sudamérica»43. De este modo, si bien se planteaba una visión moderna de la ciudad, ella era subsumida en una visión universalista que le negaba cualquier especificidad.

Esta impronta fue asimismo llevada a la elección de la actriz principal del film. Mientras que la crítica de los Estados Unidos había señalado que el papel protagónico de Mirtha Legrand presentaba a una rubia más parecida a las actrices de Hollywood, al momento de rehacer la película Columbia descartó ese perfil para priorizar una intérprete que personificara los atributos de fogosidad y sensualidad asociados al ideal hegemónico de la mujer latina. El reemplazo de la rubia ingenua por la pelirroja Rita Hayworth es así uno de los principales puntos que muestran el espíritu de esta adaptación.

Esta elección plantea una distancia entre Bailando nace el amor y las películas asociadas tradicionalmente con la política del Buen Vecino, donde la estrella femenina respondía más bien a una imagen claramente identificable como latina, pero cuya sexualidad no implicaba poder. Ana López identifica

[43] En el original: «He's not leaving South America». 

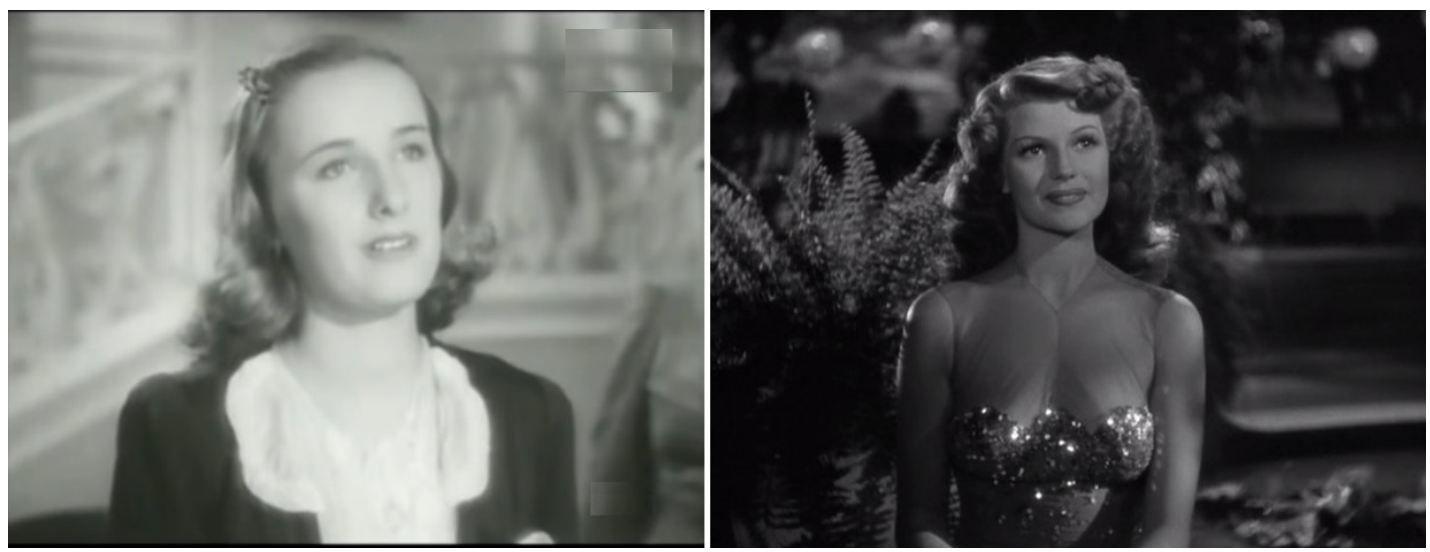

La ingenua encarnada por Mirtha Legrand en Los martes, orquídeas se convirtió en la fogosa latina interpretada por Rita Hayworth en Bailando nace el amor.

[44] Ana M. López, «Are All Latins from Manhattan?: Hollywood, Ethnography and Cultural Colonialism».

[45] Estos elementos suscitaron quejas desde Argentina frente a la OCIAA, que incluían también reclamos respecto al número musical protagonizado por los Nicholas Brothers, un dúo de bailarines afroamericanos. Según señala Brian O’Neil, ello despertaba el temor de que se creyera que en Argentina había población negra en contraste con la imagen blanca y cosmopolita que se pretendía ofrecer. Brian O’Neil «The Demands of Authenticity». este imaginario con la figura de Carmen Miranda y sostiene que su presencia respondía más bien a una fetichización de lo latino que, a partir de la personalidad de la actriz, excedía lo mimético y se convertía en una construcción autoconsciente de esta identidad ${ }^{44}$. Esa latinidad se hacía presente en films como Serenata tropical, donde Argentina era un país rural en el que la actriz cantaba en portugués, el protagonista masculino encarnado por Don Ameche terminaba sus bailes con gritos de «olé» y los personajes locales eran sujetos cómicos con dificultad para hablar inglés ${ }^{45}$.

La presencia de Rita Hayworth en el remake de Los martes, orquídeas, en cambio, incorporaba un personaje femenino cuya función no era solamente fetichista, sino que cumplía un rol simbólico en los idearios que se pretendían relacionar con su identidad latina. En la escena donde Bob, desde su lugar de turista estadounidense, cortejaba a María, sus palabras se centraban en la modernidad apabullante de la ciudad y señalaba las profundas diferencias que presenta con su pequeño pueblo natal. Es así que la protagonista no era solamente la representación de una latina, sino también de una mujer moderna y sofisticada. La eventual concreción de la pareja supondría así el fortalecimiento de un vínculo panamericano en el que confluyeran armónicamente una América Latina cosmopolita y un Estados Unidos sencillo encarnados en los dos protagonistas.

Este mismo cosmopolitismo estaba presente en Romance en alta mar, pero con la marcada diferencia de que, mientras en Bailando nace el amor los personajes latinos ocupaban un rol protagónico y el romance principal era transnacional, aquí todos los papeles principales eran estadounidenses y América Latina pasaba a ser un trasfondo de las acciones. La importancia que las políticas de Buena Vecindad habían dado a la presencia de la región en el cine de comienzos de la década pasó así a convertirse en un legado de ambientes posibles para los relatos. 


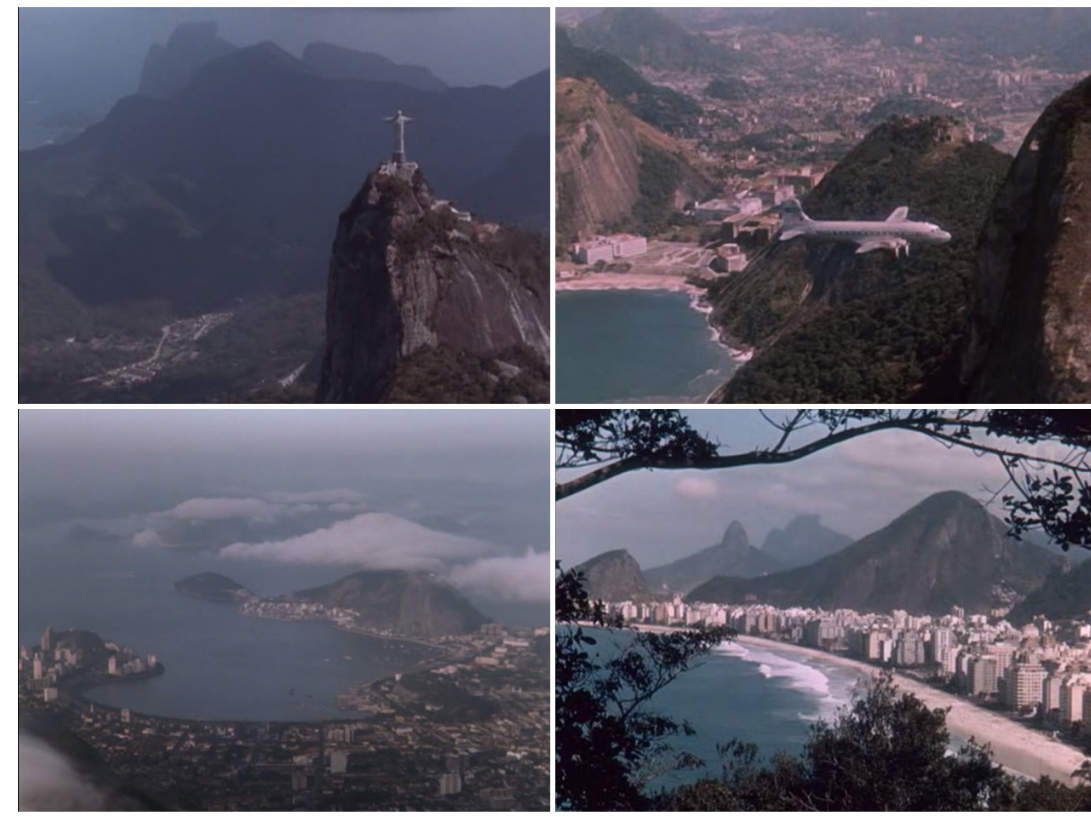

Registros documentales de Río de Janeiro en Romance en alta mar (Romance on the High Seas, Michael Curtiz, 1948)

Los discursos vinculados a la confraternidad panamericana quedaron reducidos en Romance en alta mar a un comentario cómico efectuado por uno de los personajes. Cuando hacia el final del film la protagonista discute con un amigo la posibilidad de que otro personaje femenino estadounidense cante una canción en público en Río de Janeiro, este le responde que, si lo hace, «hará retroceder la política de buena vecindad 20 años». De este modo, si bien no se negaba la pervivencia de esta cosmovisión, ya no necesita ser promovida activamente y podía ser puesta en ridículo.

La falta de integración entre Estados Unidos y América Latina conllevaba asimismo una redefinición de la representación de los espacios, que comenzó a asemejarse cada vez más a la que el cine de Hollywood planteaba con otras partes del mundo. Como señala Fiona Handyside, hacia finales de los años cuarenta, el musical de Hollywood pasó a centrarse en ambientaciones parisinas y romanas, siempre con un personaje que sirviera de mediador para el público de los Estados Unidos. La autora propone que la «mirada turista» construía una visión utópica de estos espacios que permitía a los films llevar ahí las tensiones y preocupaciones de la posguerra ${ }^{46}$. Es así que la representación de las ciudades de América Latina, que había sido construida alrededor del escapismo y el aseguro de la primacía estadounidense en tiempos del conflicto, empezó a asimilar formas vinculadas a otros espacios urbanos.

En Romance en alta mar la idea turística predominaba claramente en la representación y la temática del film. Los créditos iniciales del film se repro-
[46] Fiona Handyside, «Colonising the European Utopia: Hollywood Musicals in Europe», en Paul Cooke (ed.), World Cinema's 'Dialogues' with Hollywood (New York, Palgrave Macmillan, 2007), pp. 138-153. 
[47] Como señala Arthur Autran, estas formas de representación de Brasil a partir de la imagen turística de Río de Janeiro no eran exclusivas del cine de Hollywood, sino que también se podían encontrar, por ejemplo, en films argentinos como Caminito de gloria (Luis César Amadori, 1939) o No me digas adiós (Luis Moglia Barth, 1950). Arthur Autran, «Namorando o Brasil: o caso do filme Romance no Rio» (RuMoRes vol. 12, $\mathrm{n}^{\circ}$ 24, diciembre de 2018), pp. 212-230.

[48] Doris Day no fue la primera actriz elegida para el papel, sino que inicialmente Warner Bros. intentó conseguir a Lauren Bacall. Luego de que esta rechazara el papel se consideraron distintos nombres como Alice Faye, Ginger Rogers, Paulette Goddard, Janis Paige y Marian Hutton hasta decidirse por Day. Estos nombres demuestran claramente la intención de los productores de deshacerse de cualquier rasgo de latinidad del personaje para priorizar su identificación con el público estadounidense. «Inter-Office Communication, April 15, 1947» en carpeta «Romance on the High C», de Jack Warner Collection (Special Collection USC), Warner Bros. Archive. ducían sobre dibujos de postales, y la protagonista era introducida como una eterna soñadora que aspiraba algún día a poder viajar a algún destino lejano. De igual modo, la llegada a Río era presentada con un montaje de tomas aéreas que retomaban las imágenes de promoción de la ciudad, entre las cuales se contaban el Cristo del Corcovado y las playas paradisíacas. Esta modalidad que retomaba explícitamente las formas de representación del campo del turismo reforzaba la lejanía entre los ambientes y los personajes protagónicos ${ }^{47}$.

La separación de los protagonistas del ambiente latino fue reforzada en Romance en alta mar con la elección de la actriz principal. Resulta sumamente interesante que, así como en Bailando nace el amor la ingenua adolescente rubia había sido reemplazada por una fogosa latina pelirroja, aquí el proceso fue exactamente el contrario. La figura de la cantante de tangos de pelos negros y carácter decidido que interpretaba Libertad Lamarque se convirtió aquí en una clásica rubia estadounidense a través del personaje que lanzó al estrellato a Doris Day y comenzó a construir su imagen de All-American Girl ${ }^{48}$.

Los personajes latinos pasaron a ser así solamente un componente del ambiente, mientras que, con la elección de Jack Carson como el detective, el protagonismo recayó en una pareja estadounidense. La ingenuidad e inocencia que caracterizaron a los personajes de la actriz la convirtieron así en portavoz ideal de la mirada deslumbrada del estadounidense que, en un contexto de paz de posguerra, salía a conocer el mundo. Lo latino fue reducido al ambiente y la música, pero ya no se buscaba un romance que permitiera su unión con los Estados Unidos.

Esta predilección por la mirada de los estadounidenses iba acompañada, sin embargo, con una marcada atención a los detalles. Una de las principales quejas recibidas a lo largo de los primeros años en que se produjeron los musicales de ambientación latinoamericana había sido la representación de la región como un todo indistinto que borraba las particularidades locales. Para afrontar estos reclamos se creó en 1941 una dirección dentro de la Administración del Código
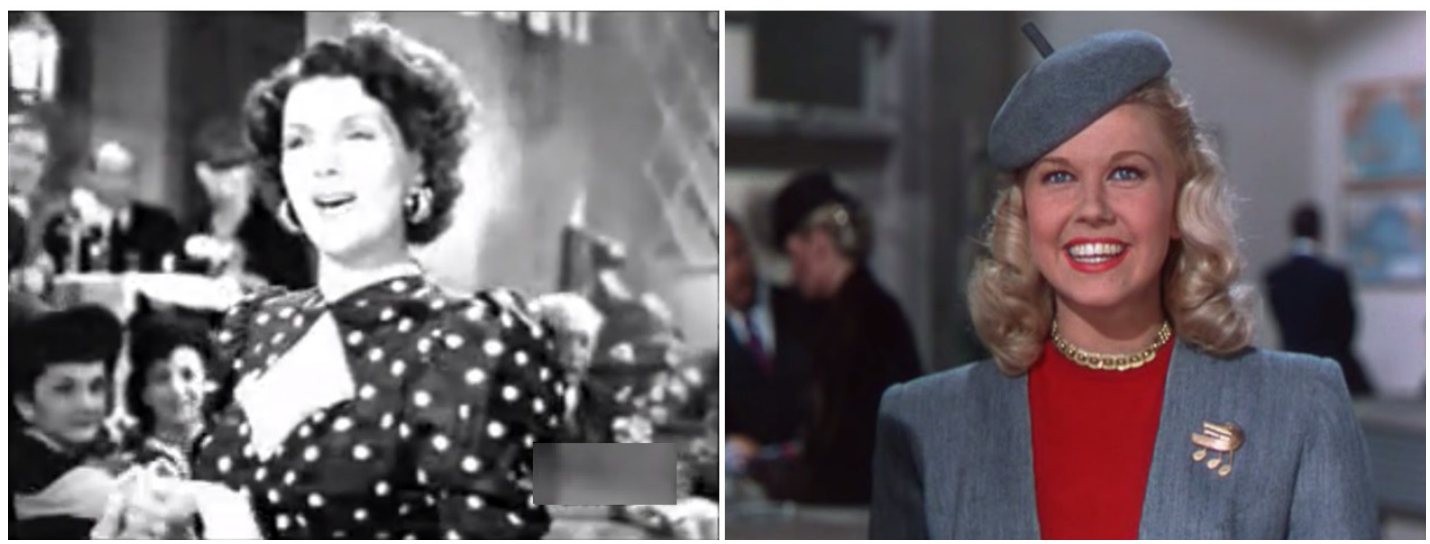

La morocha argentina encarnada por Libertad Lamarque en Romance musical se convirtió en la rubia americana interpretada por Doris Day en Romance en alta mar. 
de Producción para supervisar las producciones de temática latinoamericana y corregir lo que se consideraba como errores en su representación.

Estas tareas construyeron gradualmente una imagen moderna, cosmopolita y blanca de América Latina ${ }^{49}$. Si bien en Bailando nace el amor estas políticas no tuvieron impacto, es posible percibirlo en la forma en que se representó América Latina en Romance en alta mar. Las tres escalas que realizaba el crucero en La Habana, Trinidad y Río eran acompañadas por objetos que hacían referencia a cada lugar y ritmos musicales asociados a cada uno de ellos.

Un claro ejemplo de esta atención al detalle se puede percibir al comparar dos borradores del guion. En la versión del 9 de enero de 1947, dos personajes tomaban un vuelo en Trinidad buscando escapar a Nueva York, pero por equivocación se dirigían a Río. A partir de ello, sostenían el siguiente diálogo:

$$
\begin{aligned}
& \text {-¿ंNo pediste boletos a Nueva York? } \\
& \text {-Ciertamente - en mi mejor español. } \\
& \text {-¿Alguna vez estudiaste español? } \\
& \text {-No. ¿Crees que pudo haber tenido algo que ver con esto?50 }
\end{aligned}
$$

La versión final del guion, fechada el 14 de mayo de 1947, presentaba una versión distinta de este diálogo:

-¿No pediste boletos a Nueva York?

-Ciertamente - en mi mejor español.

-Pero el lenguaje oficial de Trinidad es inglés.

- Oh. ¿Crees que pudo haber tenido algo que ver con esto? ${ }^{51}$

Entremedio de ambas versiones, Hetta George, cabeza del Research Department de Warner Bros., había escrito a Michael Curtiz una nota donde le indicaba:

El inglés es el único lenguaje hablado en TRINIDAD con la excepción del patois francés que usan los negros de la clase esclava. No se debería esperar que un agente de viajes entienda si se le habla en español, y, de hecho, si el agente fuera un hombre de color, que bien podría serlo en Trinidad, hablarle en un lenguaje reminiscente del patois sería ofensivo ${ }^{52}$.

Esta creciente atención al detalle ya no era, sin embargo, una táctica para atraer a los públicos latinoamericanos, sino que era parte de la creación de una esfera global frente a la mirada de los espectadores estadounidenses de posguerra. Se puede pensar así que esta búsqueda de una representación correcta apuntaba más bien a una estrategia comercial de no ofender posibles mercados más que a una preocupación diplomática para asegurarse el apoyo político de la región.

\section{Consideraciones finales}

Los dos remakes abordados en este artículo presentan una serie de factores que, si bien corresponden a casos puntuales, permiten considerar aspectos de gran interés en lo que hace a las relaciones entre Argentina y Estados Unidos, la diná-
[49] La imagen racial era uno de los principales reclamos que se hacían desde los países latinoamericanos que rechazaban la presencia de intérpretes afroamericanos encarnando personajes brasileros o argentinos. Véase Brian O’Neil «The Demands of Authenticity».

[5o] En el original:

-Didn't you ask for tickets to New York?

-I certainly did - in my best Spanish

-Did you ever study Spanish?

-No. Do you think that had anything to do with it?

«Screenplay Draft» en carpeta «Romance on the High Seas Story - Screenplay - 1/9/47», Warner Bros. Archive.

[51] En el original:

-Didn't you ask for tickets to New York?

-I certainly did - in my best Spanish

-But the official language of Trinidad is English

-Oh. Do you think that had anything to do with it?

«Screenplay Revised Final» en carpeta «Romance on the High Seas - Story - Revised Final - 5/14/47», Warner Bros. Archive.

[52] En el original: «English is the only language spoken in TRINIDAD with the exception of a French patois used by negroes of the servant class. A ticket agent could not be expected to understand if he was addressed in Spanish, and, as a matter of fact, if the ticket agent were a colored man which he might well be in Trinidad, to be addressed in a foreign language reminiscent of the lowly patois, would be offensive». InterOffice Communication de Hetta George a Michael Curtiz, April 8, 1947, en carpeta «Romance on the High C», de Jack Warner Collection (Special Collection USC), Warner Bros. Archive. 
mica de la circulación de textos dramáticos en el período clásico y las tensiones en la representación de lo local y lo universal. Los cambios entre ambos casos producidos en lo que respecta a la configuración de los protagonistas, la relación entre los personajes estadounidenses y el entorno latino de la acción y la representación de los espacios latinoamericanos plantean un desplazamiento afín a las transformaciones que implicaron los procesos de producción de ambos casos.

La adaptación de Los martes, orquídeas fue pensada como el inicio de un proceso duradero de colaboraciones comerciales entre los dos países en un contexto de marcado interés por América Latina desde Hollywood y Washington, lo cual fue celebrado inicialmente en ambos países. Ello implicó la propuesta de un romance transnacional ambientado en Buenos Aires en Bailando nace un amor, pero con un espíritu de fraternidad panamericana que subsumía las particularidades rioplatenses a una identidad regional cosmopolita.

Romance musical, en cambio, fue el producto de la iniciativa comercial de sus guionistas y consistió en un caso que fue tratado con desinterés en Argentina mientras que se incorporó a una serie de musicales de factura industrial con los que el cine estadounidense apeló a los públicos internacionales en la posguerra. De este modo, los espacios latinoamericanos pasaron a ser simplemente escenarios urbanos y modernos para las acciones de los estadounidenses y, si bien se prestó mayor atención a los detalles de representación, ya no se buscó la integración panamericana.

El análisis de estos casos permite, por lo tanto, iluminar dinámicas poco consideradas en las investigaciones sobre la historia del cine argentino, sus relaciones con los Estados Unidos y las circunstancias que rodearon las políticas de Buena Vecindad en los años cuarenta. Los acercamientos iniciales entre ambos países antes del acuerdo de Hollywood con la industria mexicana, el accionar de agentes privados a lo largo de la década y el impacto de ello sobre la producción y las formas de representación del cine argentino y estadounidense son algunos de los aspectos que surgen en este trabajo y permiten pensar en la necesidad de complejizar las miradas sobre este campo. Asimismo, se abren interrogantes sobre el entrecruzamiento de las industrias cinematográficas y musicales, el rol de los imaginarios turísticos y la recepción de estas películas que invitan a profundizar en el estudio de estas y otras realizaciones afines que no han sido suficientemente abordadas por la bibliografía existente.

El estudio de los remakes transnacionales resulta, por lo tanto, un terreno que enriquece los trabajos de la historiografía al plantear vías alternativas para considerar tanto las prácticas industriales como los modelos de representación. De este modo, se ponen en foco miradas alternativas sobre problemáticas recurrentes de las investigaciones históricas como la pregunta por lo «nacional», los sistemas de géneros y estrellas y los desarrollos industriales. Una mayor profundización en este campo permitirá de a poco construir nuevas cartografías que den cuenta de redes de circulación e intercambios poco consideradas hasta el momento. 


\section{Fuentes}

Collection Motion Picture Society for the Americas. Depositado en Special Collections, Margaret Herrick Academy of Motion Picture Arts and Sciences Library, Beverly Hills, CA, Estados Unidos.

«Folder Argentina-Report»

Collection Number Mo192. Guide to Delmer Daves Papers 1930-1965. Depositado en Department of Special Collections, Stanford University Libraries, Stanford, CA, Estados Unidos.

«You Were Never Lovelier-Revised Final Draft», Caja 11, Carpeta 13.

Warner Bros. Archive. Depositado en School of Cinematic Arts, University of Southern California, Los Angeles, CA, Estados Unidos.

«Facsímil del contrato de Olivari y Pondal Ríos con Estudios San Miguel, 30 de julio de 1945». Carpeta «Romance on the High Seas, Story File, 2 of 4».

Nota escrita a mano. Carpeta «Romance on the High Seas, Story File, 3 of 4».

«Screenplay Draft». Carpeta «Romance on the High Seas - Story - Screenplay - 1/9/47». Inter-Office Communication de Hetta George a Michael Curtiz, April 8, 1947. Carpeta «Romance on the High C, from Jack Warner Collection (Special Collection USC)». «Screenplay Revised Final». Carpeta «Romance on the High Seas - Story - Revised Final- 5/14/47».

\section{Referencias Hemerográficas}

«Argentina's Best Sellers» (Variety, vol. 152, n. ${ }^{\circ}$ 4, 6 de octubre de 1943), p. 46. «Argentine Pix Seek Distrib Extension in U.S.; Shauer, Moreno Behind Move» (Variety, vol. 144, n. ${ }^{\circ} 3,24$ de septiembre de 1941), p. 16.

«"Bailando nace el amor" se posterga; continuará "Mi secretaria brasileña” (La Nación, 5 de mayo de 1943), p. 8.

«Buen humor y canto en "Romance musical” (La Nación, 23 de enero de 1947), p. 8.

«Nueve canciones y un enredo risueño en "Romance musical” (El Mundo, 23 de enero de 1947), p. 14.

«Los martes, orquídeas» (Variety, vol. 143, n. ${ }^{\circ}$ 3, 25 de junio de 1941), p. 20.

«Producción argentina» (Heraldo del cinematografista, vol. XII, n. ${ }^{\circ}$ 551, 11 de marzo de 1942), p. 33.

Publicidad de Romance musical (La Nación, 22 de enero de 1947), p. 8.

«Se ha estrenado, con "Los martes, orquídeas", la mejor comedia filmada en el país» (Radiolandia, $n .^{\circ}$ 691, 14 de junio de 1941), s/d.

«Sin título» (Sintonía, año VII, 29 de octubre de 1941, n 407 ).

Josephs, Ray «Argentine Films Show Signs of Leading Spanish Field» (Variety, vol. 145, n. ${ }^{\circ}$ 5, 7 de enero de 1942), p. 91.

MARLOWE, June, «El candor romántico de "Los martes, orquídeas" perdiose en su nueva concepción espectacular» (Radiolandia, $n .^{\circ}$ 779, 20 de febrero de 1943), s/d.

Petit de Murat, Ulyses, «Significado del éxito de "Los martes, orquídeas" (Crítica, n. ${ }^{\circ}$ 9282, 9 de junio de 1941), s/d. 


\section{Bibliografía}

Afron, Charles y Afron, Mirella Jona, Best Years: Going to the Movies, 1945-1946 (New Brunswick/Londres, Rutgers University Press, 2009).

Autran, Arthur, «Namorando o Brasil: o caso do filme Romance no Rio» (RuMoRes, vol. 12, n. $^{\circ}$ 24, diciembre, 2018), pp. 212-230

BAZIN, André, «Remade in USA» (Cahiers du Cinema, vol.2, n. $\left.{ }^{\circ} 11,1952\right)$, pp. 54-59.

Bender, Penee, Film as an Instrument of the Good Neighbor Policy, 1930s-1950s (Ann Arbor, UMI Microform, 2002).

CAmpodónico, Raúl Horacio, Trincheras de celuloide. Bases para una historia políticoeconómica del cine argentino (Madrid, Fundación Autor, 2005).

ForRest, Jennifer y Koos, Leonard (eds.), Dead Ringers: The Remake in Theory and Practice (Albany, State University of New York Press, 2002).

Freire-Medeiros, Bianca, «Hollywood Musicals and the Invention of Rio de Janeiro, 1933-1953» (Cinema Journal, vol. 41, n. ${ }^{\circ}$ 4, verano, 2002), pp. 52-67.

HANDYSIDE, Fiona, «Colonising the European Utopia: Hollywood Musicals in Europe», en Paul Cooke (ed.), World Cinema's 'Dialogues' with Hollywood (Nueva York, Palgrave Macmillan, 2007), pp. 138-153.

Kelly Hopfenblatt, Alejandro, «Remakes y nuevas versiones en el marco de las industrias fílmicas de Argentina y México: tensiones entre las improntas nacionales y las ansias universales», en Ana Laura Lusnich, Alicia Aisemberg y Andrea Cuarterolo (eds.), Pantallas trasnacionales. El cine argentino y mexicano del período clásico (Buenos Aires, Imago Mundi, 2017), pp. 87-101.

-, Modernidad y teléfonos blancos. La comedia burguesa en el cine argentino de los años '4o (Buenos Aires, Ciccus, 2019)

KrIGer, Clara, Cine y peronismo. El Estado en escena (Buenos Aires, Siglo XXI, 2009). LIE, Nadia, «Lo transnacional en el cine hispánico: deslindes de un concepto», en Robin Lefere y Nadia Lie (eds.), Nuevas perspectivas sobre la transnacionalidad del cine hispánico (Leiden/Boston, Brill Rodopi, 2016), pp. 17-35.

LóPEz, Ana M., «Are All Latins from Manhattan?: Hollywood, Ethnography and Cultural Colonialism», en John King, Ana M. López y Manuel Alvarado (eds.), Mediating Two Worlds: Cinematic Encounters in the Americas (Londres, BFI, 1993), pp. 6780.

Morales, Iván, «Luis Saslavsky: Hollywood vivido e imaginado» (AURA. Revista de Historia y Teoría del Arte, . $^{\circ}$ 4, septiembre de 2016), pp. 31-53.

-, «"Las sombras llaman a mi puerta”: John Alton y el melodrama en Puerta cerrada (1939)» (Studies in Spanish \& Latin American Cinemas, vol. 16, n. ${ }^{\circ}$ 3, septiembre, 2019), pp. 295-314.

-, «Escala en Buenos Aires: los primeros años de John Alton en el cine argentino» (Imagofagia, n. ${ }^{\circ}$ 17, abril, 2018), pp. 149-188.

O’NeiL, Brian, «The Demands of Authenticity. Addison Durland and Hollywood's Latin Images during World War II», en Daniel Bernardi (ed.), Classic Hollywood, Classic Whiteness (Minneapolis, University of Minnesota Press, 2001), pp. 359-385.

Peredo Castro, Francisco, Cine y propaganda para Latinoamérica. México y Estados Unidos en la encrucijada de los años cuarenta. (México D.F., Centro de Investigaciones sobre América Latina y el Caribe, Universidad Nacional Autónoma de México, 2011). 
Purcell, Fernando, iDe película! Hollywood y su impacto en Chile, 1910-195o (Santiago, Taurus, 2012).

Quaresima, Leonardo, «Loving Texts Two at a Time: The Film Remake» (CiNéMAS, vol. $\left.12,{ }^{\circ}{ }^{\circ} 3,2002\right)$, pp. $73-84$.

Shaw, Lisa, Conde, Maite, «Brazil through Hollywood's Gaze: From the Silent Screen to the Good Neighbor Policy Era», en Lisa Shaw y Stephanie Dennison (eds.), Latin American Cinema: Essays on Modernity, Gender and National Identity (Jefferson, NC: McFarland Press, 2005), pp. 180-209.

Smith, Iain Robert, Verevis, Constantine, Transnational Film Remakes (Edinburgh, Edinburgh University Press, 2017).

Verevis, Constantine, Film Remakes (Edimburgo, Edinburgh University Press, 2006).

WALTERs, Debra Nan, Hollywood, World War II, and Latin America: The Hollywood Good Neighbor Policy as Personified by Carmen Miranda (Tesis Doctoral, Los Angeles, University of Southern California, 1978).

Recibido: 22 de abril de 2019

Aceptado para revisión por pares: 15 de noviembre de 2019

Aceptado para publicación: 28 de febrero de 2020 